\title{
A novel multi-objective bi-level programming problem under intuitionistic fuzzy environment and its application in production planning problem
}

\author{
V. P. Singh ${ }^{1} \cdot$ Kirti Sharma $^{1} \cdot$ Debjani Chakraborty $^{2} \cdot$ Ali Ebrahimnejad $^{3}$
}

Received: 7 June 2021 / Accepted: 22 January 2022 / Published online: 20 February 2022

(c) The Author(s) 2022

\begin{abstract}
This paper presents an optimization method to solve a multi-objective model of a bi-level linear programming problem with intuitionistic fuzzy coefficients. The idea is based on TOPSIS (technique for order preference by similarity to ideal solution) method. TOPSIS method is a multiple criteria method that identifies a satisfactory solution from a given set of alternatives based on the minimization of distance from an ideal point and maximization of distance from the nadir point simultaneously. A new model of multi-objective bi-level programming problem in an intuitionistic fuzzy environment has been considered. The problem is first reduced to a conventional multi-objective bi-level linear programming problem using accuracy function. Then the modified TOPSIS method is proposed to solve the problem at both the leader and the follower level where various linear/non-linear membership functions are used to represent the flexibility in the approach of decision-makers (DMs). The problem is solved hierarchically, i.e., first the problem at the leader level is solved and then the feasible region is extended by relaxing the decision variables controlled by the leader. The feasible region is extended to obtain a satisfactory solution for the DMs at both levels. Finally, the application of the proposed approach in the production planning of a company has been presented. An illustrative numerical example is also given to explain the methodology defined in this paper.
\end{abstract}

Keywords Multi-objective optimization problem · Bi-level programming problem · TOPSIS method · Intuitionistic fuzzy number · Fuzzy optimization

\section{Introduction}

K. Sharma and D. Chakraborty contributed equally to this work

V. P. Singh

vpsingh@mth.vnit.ac.in

Kirti Sharma

unik96kirti@gmail.com

Debjani Chakraborty

debjani@maths.iitkgp.ac.in

Ali Ebrahimnejad

aemarzoun@gmail.com; a.ebrahimnejad@qaemiau.ac.ir

1 Department of Mathematics, Visvesvaraya National Institute of Technology Nagpur, Nagpur 440010, Maharashtra, India

2 Department of Mathematics, Indian Institute of Technology Kharagpur, Kharagpur 721302, West Bengal, India

3 Department of Mathematics, Qaemshahr Branch, Islamic Azad University, Qaemshahr, Iran
A decentralized programming problem where a hierarchical administrative structure is used to arrange multiple decision makers (DMs) can be easily modelled using a multi-level programming problem. A bi-level programming problem (BLPP) is one of the special cases of multi-level programming problem. In BLPP, two DMs are located at two different hierarchical levels. Both the DMs in bi-level programming problem control one subset of decision variables and they have different (maybe conflicting) objectives. In BLPP, the upper level DM is termed as the leader and the lower level $\mathrm{DM}$ is termed as the follower. Following the hierarchy, the leader makes a decision first. Depending upon the decision of the leader, the follower chooses his/her strategy. The strategy of follower may affect the objectives achieved by the leader. The behaviour of the leader influences the strategy of follower; whose decisions may in turn affect the leader. As a result of this dependency, the decision deadlocks are natural to arise. In practical decision-making situations, the 
problem of proper distribution of decision power to DMs is also encountered.

Real-world optimization problems consist of the situations when DMs at both the levels aim to optimize more than one objective. This gives rise to multi-objective bi-level optimization problems. In the presence of multiple conflicting objectives, usually, one solution can not optimize all the objectives. So, an efficient solution is needed. Modelling reallife optimization problems also presents difficulties because of imprecise technological coefficients. The introduction of fuzzy set theory simplified the task of representing imprecise information with the help of fuzzy numbers. In real life problems, such imprecise coefficients have uncertainty associated in the form of membership as well as non-membership degree. The use of intuitionistic fuzzy numbers (IFNs) make it easier to handle such imprecise information and thus are important to use while defining such situations. So, in this work, a multi-objective bi-level linear programming problem in an intuitionistic fuzzy environment is considered for solving such optimization problems.

The problem of optimization of multiple objectives at multiple levels with imprecise technological coefficients is often faced by various organizations. For example, consider the case of diet-planning problem faced by hospital authorities. In such a case, the nutritionist serves as leader and the kitchen manager serves as follower. The objective of nutritionist is to provide the nutritious food and the food with lesser cholesterol (the objectives at leader level) and the objective of kitchen manager is to provide the food that can be prepared with lesser cost and the food that gives a maximum profit (the objectives at follower level); keeping in mind the nutritional requirements of the patients (the constraints). The coefficients which are used to represent the information such as nutrition, cost and profit associated with various types of food can never be told precisely because these coefficients vary according to market conditions or according to the various types of food packets used. Since the knowledge and semantic representation becomes more meaningful and applicable when the information is revealed by a logical DM. The decision of a logical DM not only takes into account the impreciseness of data but they also take into account the hesitation associated with that data. This hesitation can be best represented when in addition to the degree of membership, a degree of non-membership is also defined which is not the exact complement of degree of membership. Thus, the coefficients discussed need to have uncertainty not only in presenting the degree of membership but also in presenting the degree of non-membership. To handle such coefficients, IFNs are used. Such problems also exist in production planning when the leader and follower wishes to optimize a certain set of objectives at their separate levels in the hierarchy under given constraint in an uncertain environment. This type of optimization problems can be handled by developing methods for solving multi-objective bi-level optimization problem with IFNs.

In this work, a solution methodology for solving a multiobjective bi-level optimization problems under intuitionistic fuzzy environment has been modelled. The TOPSIS method has been modified to solve the problem under consideration, so, the efficient solution is supposed not only to have a minimum distance from positive ideal solution but also a maximum distance from the negative ideal solution. Thus, the obtained solution serves as one of the best choices. The coefficients of constraints are not defuzzified and hence no important information is lost during the solution procedure. The proposed work can be extended for solving optimization problems where decisions are made hierarchically and each level in the hierarchy aims at optimizing multiple objectives. In this work, only two levels in the hierarchy are considered. To the best of author's knowledge in the problem domain, the optimization of multiple objectives in two levels in an intuitionistic fuzzy environment has never been formulated till date.

\section{Literature review}

The very first work regarding the solution procedure of BLPP was presented by Candler and Townsley [1] in 1982. Some surveys which present both new solution approaches and theoretical results for solving BLPP are [2-5]. In [6], Moitra and Pal solved BLPP using fuzzy goal programming methods. Degree of satisfaction for optimality of objectives at both the levels was maximized while keeping in mind the optimality of decision variables controlled by the leader. Arora and Gupta [7] used dynamic fuzzy goal programming approach and divided the problem into two phases. In their work, the feasible region was determined in the first phase. The second phase dealt with the attainment of objective functions of leader and follower and optimization of decision variables controlled by the leader. In [8], Wan et al. proposed an interactive fuzzy decision making method to solve BLPP where the leader and the follower had a common decision variable. An interactive fuzzy decision making method for solving BLPP was also presented by Zheng et al. [9]. They introduced a balance function which tackled the problem of improper distribution of decision powers. Researchers like Pramanik Roy [10], Sinha et al. [11] developed approaches based on fuzzy programming to solve multi level linear programming problem.

Handling multiple objectives comes handy while solving real-life optimization problems. While solving multiobjective optimization problem, an optimal solution to one objective may not optimize all the objectives and in such situations, a solution which performs no worse than any other solution is searched. Such a solution is known as an efficient solution. There are various methods defined in the literature 
to solve multi-objective optimization problem. Zimmerman [30] proposed an approach for solving multi-objective optimization problem using fuzzy programming. Optimality conditions for non-smooth multi-objective bi-level problems were discussed by TD Chuong in 2020 in [31]. Gandhi et al. in [32] discussed the optimality conditions for multiobjective bi-level optimization problem involving set valued constraints. TOPSIS method is also one such method that can be used for solving multi-objective decision making problem. The method is based on the concept that any solution which is closest to the positive ideal solution and farthest from the negative ideal solution is a good choice for the efficient solution. Hwang and Yoon [33] were first to develop the method for solving multiple attribute decision making problem and further the method was extended by many researchers in [3436] and [37], to solve multi-objective optimization problems. Table 1 presents the literature survey in a gist.

In real-life situations, the precision of the technological coefficients while solving multi-objective bi-level optimization problem is not always guaranteed. A precise data may also lead to higher information retrieval cost. Thus, an imprecise data is considered while solving such real-world optimization problems. Fuzzy set theory can be extensively used to capture such impreciseness and vagueness in the data. In fuzzy set theory, corresponding to every element, a degree of membership is given. Psychologically, linguistic expression for defining the degree of non-membership is not the exact complement of the degree of membership, because a logical DM also takes into account the hesitancy corresponding to its decisions. However, there is no way to model such hesitancy in fuzzy set theory. Intuitionistic fuzzy sets, introduced by Atanassov [38] address this issue in addition to the impreciseness. IFNs can be used to handle such coefficients which have a component of hesitation in addition to impreciseness. Various researchers have worked on optimization in imprecise environment in recent decades. Decision making in an imprecise environment was introduced by Bellman and Zadeh [39]. Various works related to linear programming problem in intuitionistic fuzzy environment have also been done. In [40], a crisp decision was used for defuzzification. The use of ranking approach converts intuitionistic fuzzy coefficients into crisp numbers and thus a lot of important information representing uncertainty and hesitation is lost in this process. An application of multi-objective decision making in an intuitionistic fuzzy environment in transportation model was presented by Jana and Roy in [41]. The design of an intuitionistic fuzzy controller for synchronization of two non-identical hyperchaotic systems is proposed in [42]. In [42], the performances of intuitionistic fuzzy sliding motor controller (IFSMC) and fuzzy sliding motor controller were compared and Lyapunov stability condition is used to prove the stability of IFSMC. An intuitionistic fuzzy control method for twin rotor multi-input multi-output systems was proposed in [43]. In [43], two intuitionistic fuzzy controllers are designed which works for the main and tail rotors separately and then outputs for these two are combined. An intuitionistic fuzzy adaptive sliding mode control system for non-linear systems is designed in [44] by Kutlu et al.. In [44], the parameters of adaptive sliding mode controller are determined using intuitionistic fuzzy methods and TakagiSugeno type intuitionistic fuzzy system is used to develop the method. In [45], a hybrid approach for Modular Neural Network design using intercriteria analysis and intuitionistic fuzzy logic is proposed. It is clear from Table 1 that a lot of work has been done on BLPP, multi-objective optimization problems and on linear programming problems with IFNs separately but a combination of these three have received less attention despite of its applications. So, in this work, a multiobjective bi-level optimization problem under intuitionistic fuzzy environment is considered and a solution methodology for the same is presented.

This paper is structured as follows: Preliminaries and concepts regarding intuitionistic fuzzy set theory and distance measures have been defined in "Preliminaries and concepts". In "Problem formulation and model development", a multi-objective bi-level linear programming problem in an intuitionistic fuzzy environment has been formulated and its solution methodology is presented. "Proposed TOPSIS algorithm" presents the algorithm for the said problem. The production planning problem of a company has been discussed in "Production planning problem". The problems presented in "Problem 1" and "Problem 2" are formulated in intuitionistic fuzzy environment and are further solved using the proposed methodology. "Conclusion" comprises of the concluding remarks.

\section{Preliminaries and concepts}

In this section, some basic preliminaries of IFNs and basics of TOPSIS method have been discussed.

Definition 1 Intuitionistic Fuzzy Set [38]. Let $X$ be a universe of discourse. Then an intuitionistic fuzzy set $\tilde{A}^{I}$ in $X$ is defined by Eq. (1):

$\tilde{A}^{I}=\left\{<x, \mu_{\tilde{A}^{I}}(x), \vartheta_{\tilde{A}^{I}}(x)>: x \in X\right\}$,

where $\mu_{\tilde{A}^{I}}(x)$ and $\vartheta_{\tilde{A}^{I}}(x)$ represents the degree of membership and degree of non-membership of element $x$ in $\tilde{A}^{I}$, respectively. $h(x)=1-\mu_{\tilde{A}^{I}}(x)-\vartheta_{\tilde{A}^{I}}(x)$ represents the degree of hesitation for element $x$.

Definition 2 Triangular Intuitionistic Fuzzy Number (TIFN) [38]. A TIFN $\tilde{A}^{I}$ is an IFN with the membership function and non-membership function given by Eqs. (2) and (3), respectively. 
Table 1 Some researches on various configurations of optimization problems

\begin{tabular}{|c|c|c|c|c|c|c|c|c|}
\hline \multirow{2}{*}{$\begin{array}{l}\text { Author } \\
\text { (years) }\end{array}$} & \multicolumn{2}{|c|}{ Objective } & \multicolumn{2}{|c|}{ Type of objective } & \multicolumn{3}{|c|}{ Coefficients } & \multirow[t]{2}{*}{ Solution approach } \\
\hline & Single & Multiple & Single & Mutiple & Crisp & Fuzzy & IFN & \\
\hline $\begin{array}{l}\text { Maiti and Roy (2019) } \\
{[12]}\end{array}$ & & $\checkmark$ & $\checkmark$ & & & & $\checkmark$ & $\begin{array}{l}\text { A ranking function is used for } \\
\text { Stackelberg game with IFNs }\end{array}$ \\
\hline Said et al. (2020) [13] & & $\checkmark$ & & $\checkmark$ & $\checkmark$ & & & $\begin{array}{l}\text { Evolutionary algorithms using } \\
\text { multiple population and } \\
\text { migration scheme }\end{array}$ \\
\hline Vidhya et al. (2017) [14] & $\checkmark$ & & & $\checkmark$ & & & $\checkmark$ & $\begin{array}{l}\text { Arithmetic operations are used for } \\
\text { problems with interval valued } \\
\text { IFNs }\end{array}$ \\
\hline $\begin{array}{l}\text { Biswas and De (2016) } \\
\text { [15] }\end{array}$ & & $\checkmark$ & $\checkmark$ & & & & $\checkmark$ & $\begin{array}{l}\text { A ranking technique for IFN and } \\
\text { used it for BLPP }\end{array}$ \\
\hline $\begin{array}{l}\text { Naseeri et al. (2018) } \\
\text { [16] }\end{array}$ & $\checkmark$ & & $\checkmark$ & & & & $\checkmark$ & $\begin{array}{l}\text { Intuitionistic fuzzy primal simplex } \\
\text { method }\end{array}$ \\
\hline $\begin{array}{l}\text { Firoz Ahmad (2021) } \\
\text { [17] }\end{array}$ & $\checkmark$ & & & $\checkmark$ & & & $\checkmark$ & $\begin{array}{l}\text { Robust neutrosophic programming } \\
\text { approach }\end{array}$ \\
\hline Ghosh et al. (2021) [18] & $\checkmark$ & & & $\checkmark$ & & & $\checkmark$ & $\begin{array}{l}\text { Transformation to interval valued } \\
\text { problem using } \alpha-\beta \text { cut }\end{array}$ \\
\hline $\begin{array}{l}\text { Ebrahimnejad et al. } \\
\text { (2018) [19] }\end{array}$ & $\checkmark$ & & $\checkmark$ & & & $\checkmark$ & & $\begin{array}{l}\text { Conversion to deterministic } \\
\text { transportation problem using } \\
\text { accuracy function }\end{array}$ \\
\hline $\begin{array}{l}\text { Biswas and De (2016) } \\
\text { [15] }\end{array}$ & & $\checkmark$ & $\checkmark$ & & & & $\checkmark$ & $\begin{array}{l}\text { A ranking technique for IFN and } \\
\text { used it for BLPP }\end{array}$ \\
\hline Gupta et al. (2021) [20] & $\checkmark$ & & & $\checkmark$ & & & $\checkmark$ & $\begin{array}{l}\text { Application in logistic problem for } \\
\text { multiple product supply chain } \\
\text { network }\end{array}$ \\
\hline Alessa (2021) [21] & & $\checkmark$ & $\checkmark$ & & $\checkmark$ & & & $\begin{array}{l}\text { A minimal adequate level of } \\
\text { objective based on membership } \\
\text { degrees }\end{array}$ \\
\hline Zhao et al. (2017) [22] & & $\checkmark$ & $\checkmark$ & & $\checkmark$ & & & $\begin{array}{l}\text { Interactive fuzzy decision making } \\
\text { method }\end{array}$ \\
\hline Lv et al. (2020) [23] & & $\checkmark$ & $\checkmark$ & & & $\checkmark$ & & $\begin{array}{l}\text { An integrated chance constrained } \\
\& \text { fuzzy probabilistic approach }\end{array}$ \\
\hline $\begin{array}{l}\text { Aggarwal et al. (2013) } \\
\text { [24] }\end{array}$ & & $\checkmark$ & & & $\checkmark$ & & $\checkmark$ & $\begin{array}{l}\text { A ranking based approach which } \\
\text { minimizes non-membership } \\
\text { degree and maximizes } \\
\text { membership degree }\end{array}$ \\
\hline Malik et al. (2018) [25] & $\checkmark$ & & $\checkmark$ & & & & $\checkmark$ & $\begin{array}{l}\text { A new ranking function for IFNs } \\
\text { and used it for defuzzification of } \\
\text { the problem }\end{array}$ \\
\hline $\begin{array}{l}\text { Abbassi et al. (2021) } \\
\text { [26] }\end{array}$ & & $\checkmark$ & & $\checkmark$ & $\checkmark$ & & & $\begin{array}{l}\text { A bi-level multi-objective chemical } \\
\text { reaction optimization algorithm }\end{array}$ \\
\hline $\begin{array}{l}\text { Del Valle et al. (2020) } \\
\text { [27] }\end{array}$ & & $\checkmark$ & & $\checkmark$ & $\checkmark$ & & & $\begin{array}{l}\text { Multi-objective bi-level model for } \\
\text { investment in gas infrastructure }\end{array}$ \\
\hline Cao et al. (2021) [28] & & $\checkmark$ & $\checkmark$ & & $\checkmark$ & & & $\begin{array}{l}\text { Multi-period post-disaster relief } \\
\text { distribution }\end{array}$ \\
\hline Deb et al. (2020) [29] & & $\checkmark$ & $\checkmark$ & & $\checkmark$ & & & $\begin{array}{l}\text { Population based evolutionary } \\
\text { algorithm }\end{array}$ \\
\hline
\end{tabular}

$\mu_{\tilde{A}^{I}}(x)= \begin{cases}\frac{x-a}{b-a} & \text { if } a \leq x \leq b \\ \frac{c-x}{c-b} & \text { if } x=b \\ 0 & \text { if } b \leq x \leq c \\ 0 \text { otherwise }\end{cases}$

and

$\vartheta_{\tilde{A}^{I}}(x)= \begin{cases}\frac{b-x}{b-a^{\prime}} & \text { if } a^{\prime} \leq x \leq b \\ 0 & \text { if } x=b \\ \frac{(x-b)}{\left(c^{\prime}-b\right)} & \text { if } b \leq x \leq c^{\prime} \\ 1 & \text { otherwise }\end{cases}$ 
Fig. 1 A triangular intuitionistic fuzzy number

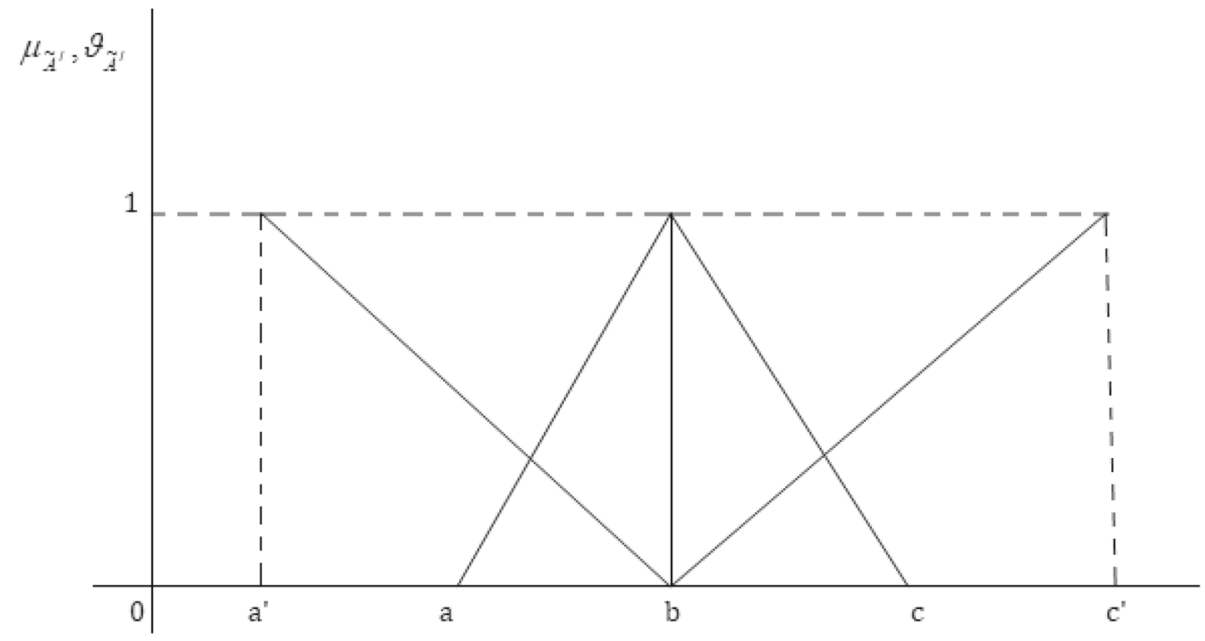

where $a^{\prime} \leq a \leq b \leq c \leq c^{\prime}$.

This TIFN is denoted by $\left(a, b, c ; a^{\prime}, b, c^{\prime}\right)$. Figure 1 represents the membership and non-membership functions of TIFN defined above. The set of all TIFNs is denoted by I $F(R)$.

Definition 3 Accuracy Function [46]. Let $\tilde{A^{I}}=\left(a, b, c ; a^{\prime}\right.$, $\left.b, c^{\prime}\right)$ be a TIFN. The score function for membership function and non-membership function is denoted by $S\left(\mu_{\tilde{A}^{I}}\right)$ and $S\left(\vartheta_{\tilde{A}^{I}}\right)$, respectively, where $S\left(\mu_{\tilde{A}^{I}}\right)=\frac{a+2 b+c}{4}$ and $S\left(\vartheta_{\tilde{A}^{I}}\right)=\frac{a^{\prime}+2 b+c^{\prime}}{4}$.

The accuracy function of $\tilde{A}^{I}$ is denoted by $f\left(\tilde{A^{I}}\right)$ and is defined by Eq. (4):

$f\left(\tilde{A}^{I}\right)=\frac{(a+2 b+c)+\left(a^{\prime}+2 b+c^{\prime}\right)}{8}$,

Definition 4 Arithmetic Operations on TIFNs [38]: Let $\tilde{A}^{I}=\left(a, b, c ; a^{\prime}, b, c^{\prime}\right)$ and $\tilde{B}^{I}=\left(p, q, r ; p^{\prime}, q, r^{\prime}\right)$ be two TIFNs, then

1. Addition: $\tilde{A^{I}} \oplus \tilde{B^{I}}=\left(a+p, b+q, c+r ; a^{\prime}+p^{\prime}, b+\right.$ $\left.q, c^{\prime}+r^{\prime}\right)$.

2. Subtraction: $\tilde{A}^{I} \ominus \tilde{B^{I}}=\left(a-r, b-q, c-p ; a^{\prime}-r^{\prime}, b-\right.$ $\left.q, c^{\prime}-p^{\prime}\right)$.

3. Multiplication: $\tilde{A}^{I} \odot \tilde{B}^{I}=\left(l_{1}, l_{2}, l_{3} ; l_{1}^{\prime}, l_{2}, l_{3}^{\prime}\right)$ where $l_{1}=\min \{a p, a r, c p, c r\} l_{3}=\max \{a p, a r, c p, c r\}$ $l_{1}^{\prime}=\min \left\{a^{\prime} p^{\prime}, a^{\prime} r^{\prime}, c^{\prime} p^{\prime}, c^{\prime} r^{\prime}\right\} l_{3}^{\prime}=\max \left\{a^{\prime} p^{\prime}, a^{\prime} r^{\prime}\right.$, $\left.c^{\prime} p^{\prime}, c^{\prime} r^{\prime}\right\} l_{2}=b q$

4. Scalar Multiplication:

$$
k \tilde{A^{I}}= \begin{cases}\left(k a, k b, k c ; k a^{\prime}, k b, k c^{\prime}\right) & \text { if } k \geq 0 \\ \left(k c, k b, k a ; k c^{\prime}, k b, k a^{\prime}\right) & \text { if } k<0\end{cases}
$$

Definition 5 Let $\tilde{A}_{1}^{I}=\left(a_{1}, b_{1}, c_{1} ; a_{1}^{\prime}, b_{1}, c_{1}^{\prime}\right)$ and $\tilde{A}_{2}^{I}=$ $\left(a_{2}, b_{2}, c_{2} ; a_{2}^{\prime}, b_{2}, c_{2}^{\prime}\right)$ be two TIFNs. Then ${\tilde{A_{1}}}^{I} \leq{\tilde{A_{2}}}^{I}$ if $a_{1} \leq a_{2}, b_{1} \leq b_{2}, c_{1} \leq c_{2} ; a_{1}^{\prime} \leq a_{2}^{\prime}, c_{1}^{\prime} \leq c_{2}^{\prime}$.

Definition 6 Distance measure. If $F(x)=\left(f_{1}(x), f_{2}(x)\right.$, $\left.\ldots, f_{m}(x)\right)$ is a vector of objective functions which is to be maximized. Then the $L_{p}$ metric defines the distance between two points $F(x)$ and $F^{*}$ as

$d_{p}=\left\{\sum_{j=1}^{m} \lambda_{j}^{p}\left[f_{j}^{*}-f_{j}(x)\right]^{p}\right\}^{1 / p}$

where $\lambda_{j} ; j=1,2, \ldots, m$ is relative importance of objective $f_{j}$ and $F^{*}=\left(f_{1}{ }^{*}, f_{2}{ }^{*}, \ldots, f_{m}{ }^{*}\right)$ where $f_{i}{ }^{*}=$ $\max _{x \in S} f_{i}(x)$. Since the objectives are not commensurable, so a scaling function in the interval $[0,1]$ should be used for every objective function. So, the following metric could be used.

$d_{p}=\left\{\sum_{j=1}^{m} \lambda_{j}^{p}\left(\frac{f_{j}^{*}-f_{j}(x)}{f_{j}^{*}-f_{j}^{-}}\right)^{p}\right\}^{1 / p} p=1,2, \ldots, m$,

where $f_{i}^{-}=\max _{x \in S} f_{i}(x)$, where $S$ is the constraint space.

\section{Problem formulation and model development}

To find an efficient solution for a multi-objective bi-level optimization problem, its formulation is required. This section deals with the formulation of the problem in an intuitionistic fuzzy environment. A modified TOPSIS method is then proposed to solve the problem. Various linear/non-linear membership functions are also defined and are used to decipher the satisfaction level of the DMs. A standard form 
of multi-objective bi-level linear optimization problem with intuitionistic fuzzy coefficients is given by Eq. (7):

$$
\begin{aligned}
& \underset{x}{\operatorname{Maximize}} \quad \tilde{Z_{1}^{I}}(x, y)=\left[\tilde{Z_{11}^{I}}(x, y), \tilde{Z_{12}^{I}}(x, y), \ldots, \tilde{Z}_{1 k_{1}}^{\tilde{I}}(x, y)\right] \\
& \text { where y solves } \\
& \text { Maximize } \quad \tilde{Z}_{2}^{I}(x, y)=\left[\tilde{Z_{21}^{I}}(x, y), \tilde{Z}_{22}^{I}(x, y), \ldots, Z_{2 k_{2}}^{\tilde{I}}(x, y)\right] \\
& \text { subject to } \quad \tilde{A}^{I} x+\tilde{B}^{I} y \leq \tilde{r}^{I} \\
& x, y \geq 0
\end{aligned}
$$

where $\tilde{Z_{i j}^{I}}=\tilde{c_{i j}^{I}} x+\tilde{d_{i j}^{I}} y$ for $i=1,2$ and $j=$ $1,2, \ldots, k_{i}$ and $x=\left(x_{1}, x_{2}, \ldots, x_{n_{1}}\right) \in \mathbb{R}^{n_{1}}$ and $y=$ $\left(y_{1}, y_{2}, \ldots, y_{n_{2}}\right) \in \mathbb{R}^{n_{2}}$ and $n_{1}+n_{2}=n$. In Eq. (7), $\tilde{A}^{I} \in I F\left(\mathbb{R}^{m \times n_{1}}\right)$ and $\tilde{B^{I}} \in I F\left(\mathbb{R}^{m \times n_{2}}\right)$ and $\tilde{r^{I}} \in I F\left(\mathbb{R}^{m}\right)$. Also, $\tilde{c}_{i j}^{I} \in I F\left(\mathbb{R}^{1 \times n_{1}}\right)$ and $\tilde{d}_{i j}^{I} \in I F\left(\mathbb{R}^{1 \times n_{2}}\right)$. The vector $\tilde{Z}_{1}{ }^{I}$ represents the objectives at the upper level and vector $\tilde{Z}_{2}{ }^{I}$ represents the objectives at the lower level. Therefore, the problem in Eq. (7) can be written as the one given by Eq. (8):

$\underset{x}{\operatorname{Maximize}} \quad \tilde{Z_{1}^{I}}(x, y)=\left[\tilde{Z_{11}^{I}}(x, y), \tilde{Z_{12}^{I}}(x, y), \ldots, \tilde{Z}_{1 k_{1}}^{\tilde{I}}(x, y)\right]$ where $y$ solves

Maximize $\quad \tilde{Z_{2}^{I}}(x, y)=\left[\tilde{Z_{21}^{I}}(x, y), \tilde{Z_{22}^{I}}(x, y), \ldots, \tilde{Z}_{2 k_{2}}^{\tilde{I}}(x, y)\right]$ subject to

$$
\begin{gathered}
\tilde{a_{i 1}^{I}} x_{1}+\tilde{a}_{i 2}^{\tilde{I}} x_{2}+\ldots+a_{i n_{1}}^{\tilde{I}} x_{n_{1}}+\tilde{r}_{i}^{I} \\
\tilde{b_{i 1}^{I}} y_{1}+\tilde{b_{i 2}^{I}} y_{2}+\ldots+b_{i n_{2}}^{\tilde{I}} y_{n_{2}} \\
x_{1}, x_{2}, \ldots, x_{n_{1}}, y_{1}, y_{2}, \ldots y_{n_{2}} \geq 0
\end{gathered}
$$

where $\tilde{Z_{i j}^{I}}(x, y)=c_{i j 1}^{\tilde{I}} x_{1}+\ldots+c_{i j n_{1}}^{\tilde{I}} x_{n_{1}}+d_{i j 1}^{\tilde{I}} y_{1}+\ldots+$ $d_{i j n_{2}}^{\tilde{I}} y_{n_{2}}$ for $i=1,2 ; j=1,2, \ldots n_{i}$. First, we use the concept of defuzzification and reduce every intuitionistic fuzzy coefficient in the objective functions to a crisp coefficient using accuracy function as defined in Eq. (4) and each intuitionistic fuzzy objective is reduced to five different crisp objective using Definition 5.

$$
\begin{aligned}
& \underset{x}{\operatorname{Maximize}} \quad Z_{1}^{\prime}(x, y)=\left[Z_{11}^{\prime}(x, y),\right. \\
& \text { where } y \text { solves } \\
& \text { Maximize } \quad Z_{2}^{\prime}(x, y)=\left[Z_{21}^{\prime}(x, y)\right. \text {, } \\
& \text { subject to } \\
& \left.Z_{22}^{\prime}(x, y), \ldots, Z_{2 k_{2}}^{\prime}(x, y)\right] \\
& \begin{array}{r}
a_{i 1_{k}} x_{1}+a_{i 2_{k}} x_{2}+\ldots+a_{i n_{k}} x_{n_{1}}+ \\
\quad b_{i 1_{k}} y_{1}+b_{i 2_{k}} y_{2}+\ldots+b_{i n_{k}} y_{n_{2}}
\end{array} \leq r_{i_{k}} ; k=1,2, \cdots 5 \\
& x_{1}, x_{2}, \ldots, x_{n_{1}}, y_{1}, y_{2}, \ldots y_{n_{2}} \geq 0
\end{aligned}
$$

where $Z_{i j}^{\prime}(x, y)=c_{i j 1}^{\prime} x_{1}+\ldots+c_{i j n_{1}}^{\prime} x_{n_{1}}+d_{i j 1}^{\prime} y_{1}+\ldots+$ $d_{i j n_{2}}^{\prime} y_{n_{2}}$ for $i=1,2 ; j=1,2, \ldots n_{i}$ where $a^{\prime}=f\left(\tilde{a}^{I}\right)$. Following the hierarchy, first an efficient solution for upper level decision maker is to be obtained. The TOPSIS model used to solve upper level multi-objective optimization problem of Eq. (9) is given by Eq. (10)

$$
\begin{array}{cc}
\text { Minimize } & d_{p}^{\mathrm{PIS}^{u}}(x, y) \\
\text { Maximize } & d_{p}^{\mathrm{NIS}^{u}}(x, y) \\
\text { subject to } & \\
& a_{i 1_{k} x_{1}+a_{i 2_{k}} x_{2}+\ldots+a_{i n_{k}} x_{n_{1}}+} \leq r_{i_{k}} ; k=1,2, \cdots 5 \\
& b_{i 1_{k} y_{1}+b_{i 2_{k}} y_{2}+\ldots+b_{i n_{k}} y_{n_{2}}} \\
& x_{1}, x_{2}, \ldots, x_{n_{1}}, y_{1}, y_{2}, \ldots y_{n_{2}} \geq 0
\end{array}
$$

where

$$
\begin{aligned}
& d_{p}^{\mathrm{PIS}^{u}}=\left\{\sum_{i=1}^{k_{1}} w_{i}^{p}\left(\frac{Z_{1 i}^{*}-Z_{1 i}}{Z_{1 i}^{*}-Z_{1 i}^{-}}\right)^{p}\right\}^{1 / p}, \\
& d_{p}^{\mathrm{NIS}^{u}}=\left\{\sum_{i=1}^{k_{1}} w_{i}^{p}\left(\frac{Z_{1 i}-Z_{1 i}^{-}}{Z_{1 i}^{*}-Z_{1 i}^{-}}\right)^{p}\right\}^{1 / p}
\end{aligned}
$$

and $Z_{1 i}^{*}=\max _{(x, y) \in S} Z_{1 i}, Z_{1 i}^{-}=\min _{(x, y) \in S} Z_{1 i}$.

$S=\left\{(x, y)=\left(x_{1}, x_{2}, \ldots x_{n_{1}}, y_{1}, y_{2}, \ldots y_{n_{2}}\right) \in \mathbb{R}^{n}:\right.$ $a_{i 1_{k}} x_{1}+a_{i 2_{k}} x_{2}+\ldots+a_{i n_{k}} x_{n_{1}}+b_{i 1_{k}} y_{1}+b_{i 2_{k}} y_{2}+\ldots+$ $b_{i n_{k}} y_{n_{2}} \leq r_{i_{k}} ; k=1,2, \ldots 5 ; x_{1}, x_{2}, \ldots, x_{n_{1}}, y_{1}, y_{2}, \ldots y_{n_{2}}$ $\geq 0 ; i=1,2, \ldots, m\}$; and $w_{i}, i=1,2, \ldots k_{1}$ are the relative weights of the objective functions such that $w_{i} \geq 0 \forall i=$ $1,2, \ldots, k_{1}$ and $\sum_{i=1}^{k_{1}} w_{i}=1$. In Eq. (11), $d_{p}^{\mathrm{PIS}^{u}}$ stands for the distance from the positive ideal solution for the objectives of upper level DM and in Eq. (12), $d_{p}^{\mathrm{NIS}^{u}}$ stands for the distance from the negative ideal solution for the objectives of upper level DM. The fuzzy goal programming model is then used to solve the bi-objective optimization problem modelled in Eq. (10). The corresponding fuzzy goal programming model is given by Eq. (13): 
Fig. 2 Linear membership functions

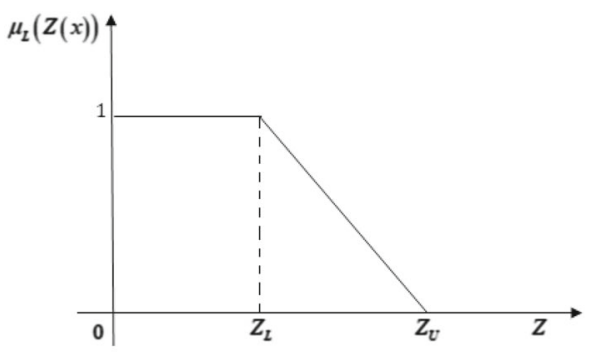

(a) Minimization objective

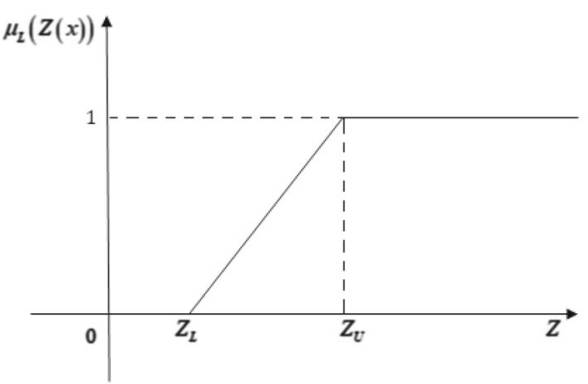

(b) Maximization of objective

Find $\quad\left\{\left(x_{i}, y_{j}\right) ; i=1,2, \ldots, n_{1}, j=1,2, \ldots, n_{2}\right\}$

subject to

$$
\begin{aligned}
& d_{p}^{\mathrm{PIS}^{u}} \approx d_{p} \mathrm{PIS}^{u *} \\
& d_{p}^{\mathrm{NIS}^{u}} \approx d_{p} \mathrm{NIS}^{u *} \\
& \begin{array}{r}
a_{i 1_{k}} x_{1}+a_{i 2_{k}} x_{2}+\ldots+a_{i n_{k}} x_{n_{1}}+ \\
b_{i 1_{k}} y_{1}+b_{i 2_{k}} y_{2}+\ldots+b_{i n_{k}} y_{n_{2}}
\end{array} \leq r_{i k_{k}} ; k=1,2, \ldots, 5 ; \\
& i=1,2, \ldots, m \\
& x_{1}, x_{2}, \ldots, x_{n_{1}}, y_{1}, y_{2}, \ldots y_{n_{2}} \geq 0
\end{aligned}
$$

where $\approx$ is a fuzzy goal, which means some deviations are allowed in strict goal. Here, $d_{p}^{\mathrm{PIS}^{u *}}=\min _{x \in S} d_{p}^{\mathrm{PIS}^{u}}$ and $d_{p}^{\mathrm{NIS}}{ }^{u *}=\max _{x \in S} d_{p}^{\mathrm{NIS}}{ }^{u}$. To change the fuzzy goal programming model into a crisp LPP, different types of linear/non-linear membership functions can be used. The use of these membership functions presents the flexibility to the DM to choose a membership function which better fits their problem and provides better aspiration levels. A linear membership function is the most utilized function in decision making process while solving mathematical programming problems. A linear approximation is defined by fixing two points, the least and most desirable levels of acceptability of an objective function. In general fuzzy set theory, such an assumption is not always justified. Thus a justification should be made considering the fuzziness of goal in mind. From this point of view, several linear/non-linear shapes of membership functions are considered.

\section{Linear membership function}

Linear membership function for minimization and maximization of an objective are given by Eq. (14) and Eq.(15), respectively, where $Z_{L}$ and $Z_{U}$ are the minimum and maximum values of the objective function $Z$, respectively.

$\mu_{L}(Z(x))= \begin{cases}1 & \text { if } Z \leq Z_{L} \\ \frac{Z_{U}-Z}{Z_{U}-Z_{L}} & \text { if } Z_{L} \leq Z<Z_{U} \\ 0 & \text { if } Z \geq Z_{U}\end{cases}$
$\mu_{L}(Z(x))= \begin{cases}0 & \text { if } Z \leq Z_{L} \\ \frac{Z-Z_{L}}{Z_{U}-Z_{L}} & \text { if } Z_{L} \leq Z<Z_{U} \\ 1 & \text { if } Z \geq Z_{U}\end{cases}$

Figure $2 \mathrm{a}, \mathrm{b}$ represents the linear membership function when the objective is to minimize and maximize an objective function $Z$, respectively.

\section{Parabolic membership function}

The parabolic membership function for minimization and maximization of an objective can be defined by Eqs. (16) and (17), respectively, where $Z_{L}$ and $Z_{U}$ are the minimum and maximum values of the objective function $Z$, respectively.

$\mu_{P}(Z(x))= \begin{cases}1 & \text { if } Z \leq Z_{L} \\ \left(\frac{Z_{U}-Z}{Z_{U}-Z_{L}}\right)^{2} & \text { if } Z_{L} \leq Z<Z_{U} \\ 0 & \text { if } Z \geq Z_{U}\end{cases}$
$\mu_{P}(Z(x))= \begin{cases}0 & \text { if } Z \leq Z_{L} \\ \left(\frac{Z-Z_{L}}{Z_{U}-Z_{L}}\right)^{2} & \text { if } Z_{L} \leq Z<Z_{U} \\ 1 & \text { if } Z \geq Z_{U}\end{cases}$

Figure $3 \mathrm{a}, \mathrm{b}$ represents the parabolic membership function when the objective is to minimize and maximize an objective function $Z$, respectively. 


\section{Hyperbolic membership function}

The hyperbolic membership function is concave over the part where the decision maker is performing better than the goal and he tends to have a small marginal rate of satisfaction and the membership function is convex over the part when the decision maker is worse off the goal and he tends to have a higher marginal rate of satisfaction. The complete functions in case of maximization and minimization of objectives are given by Eqs. (18) and (19), respectively, where $Z_{L}$ and $Z_{U}$ are the minimum and maximum values of the objective function $Z$, respectively.: tolerances $t_{k}^{L}$ and $t_{k}^{R}$ are not necessarily the same. The tolerances are provided so as to extend the feasible region for the search of the satisfactory solution. The tolerance value of the decision variables controlled by the leader are modified in a way such that the feasible region for follower is non-empty.

\section{Proposed TOPSIS method for multi-objective bi-level optimization problem}

A satisfactory solution for the multi-objective bi-level optimization problem can be obtained using the TOPSIS approach, where the objective is to minimize the distance from the

$\mu_{H}(Z(x))= \begin{cases}0 & \text { if } Z \leq Z_{L} \\ \frac{1}{2}+\frac{1}{2} \tanh \left(\left(Z(x)-\frac{Z_{U}+Z_{L}}{2}\right) \alpha_{p}\right) & \text { if } 0<Z_{L} \leq Z<Z_{U} \\ 1 & \text { if } Z \geq Z_{U}\end{cases}$
$\mu_{H}(Z(x))= \begin{cases}1 & \text { if } Z \leq Z_{L} \\ \frac{1}{2}+\frac{1}{2} \tanh \left(\left(Z(x)-\frac{Z_{U}+Z_{L}}{2}\right) \alpha_{p}\right) & \text { if } 0<Z_{L} \leq Z<Z_{U} \\ 0 & \text { if } Z \geq Z_{U}\end{cases}$

where $\alpha_{p}=\frac{6}{Z_{U}-Z_{L}}$

Figure $4 a, b$ represents the hyperbolic membership function when the objective is to minimize and maximize an objective function $Z$, respectively.

Various membership functions defined in Eqs.(14)-(19) can be used according to the satisfaction level of the decision maker and a crisp programming model of the fuzzy goal programming model is constructed. A corresponding crisp programming model is given by Eq. (20): positive ideal solution $\left(d_{p}^{\mathrm{PIS}^{B}}\right)$ and maximize the distance from the negative ideal solution $\left(d_{p}^{\mathrm{NIS}^{B}}\right)$, where $\left(d_{p}^{\mathrm{PIS}^{B}}\right)$ and $\left(d_{p}^{\mathrm{NIS}^{B}}\right)$ are given by Eqs. (21) and (22), respectively.

$d_{p}^{\mathrm{PIS}^{B}}=\left\{\sum_{i=1}^{k_{1}} w_{i}^{p}\left(\frac{Z_{1 i}^{*}-Z_{1 i}}{Z_{1 i}^{*}-Z_{1 i}^{-}}\right)^{p}\right.$

Maximize

$\lambda$

subject to

$$
\begin{aligned}
\mu\left(d_{p}^{\mathrm{PIS}^{u}}\right) & \geq \lambda \\
\mu\left(d_{p}^{\mathrm{NIS}^{u}}\right) & \geq \lambda \\
a_{i 1_{k}} x_{1}+a_{i 2_{k}} x_{2}+\ldots+a_{i n_{k}} x_{n_{1}}+ & \leq r_{i k} ; k=1,2, \ldots, 5 ; i=1,2, \ldots, m \\
b_{i 1_{k}} y_{1}+b_{i 2_{k}} y_{2}+\ldots+b_{i n_{k}} y_{n_{2}} & \\
x_{1}, x_{2}, \ldots, x_{n_{1}}, y_{1}, y_{2}, \ldots y_{n_{2}} & \geq 0
\end{aligned}
$$

An optimal solution of Eq. (20) is a vector of the form $\left(\lambda, x_{1}^{*}, x_{2}^{*}, \ldots, x_{n_{1}}^{*}, y_{1}^{*}, x_{1}^{*}, y_{2}^{*}, \ldots, y_{n_{2}}^{*}\right)$ which implies that $\left(x_{1}^{*}, x_{2}^{*}, \ldots, x_{n_{1}}^{*}, y_{1}^{*}, x_{1}^{*}, y_{2}^{*}, \ldots, y_{n_{2}}^{*}\right)$ is an efficient solution of the upper level optimization problem. According to the concept of bi-level programming technique, which states that the leader sets the value of the decision variables controlled by him, assume $t_{k}^{L}$ and $t_{k}^{R}, k=1,2, \ldots n_{1}$ be the maximum acceptable negative and positive relaxation values for decision variable $x_{k}$, respectively, controlled by the leader. The

$$
\left.+\sum_{j=1}^{k_{2}} w_{j+k_{1}}^{p}\left(\frac{Z_{2 j}^{*}-Z_{2 j}}{Z_{2 j}^{*}-Z_{2 j}^{-}}\right)^{p}\right\}^{1 / p}
$$

and

$d_{p}^{\mathrm{NIS}^{B}}=\left\{\sum_{j=1}^{k_{1}} w_{j}^{p}\left(\frac{Z_{1 j}-Z_{1 j}^{-}}{Z_{1 j}^{*}-Z_{1 j}^{-}}\right)^{p}\right.$ 
Fig. 3 Parabolic membership functions

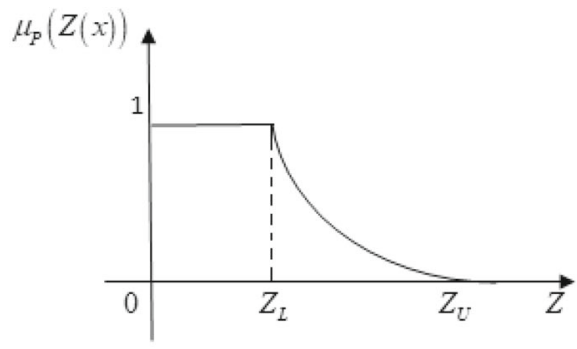

(a) Minimization of objective

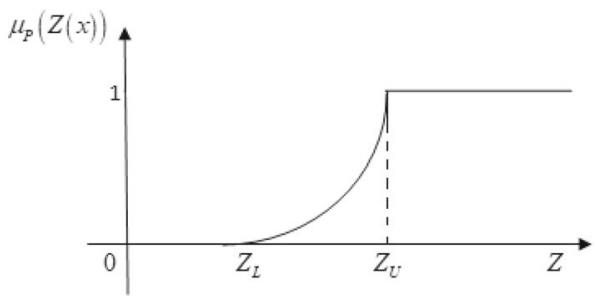

(b) Maximization of objective

Fig. 4 Hyperbolic membership functions

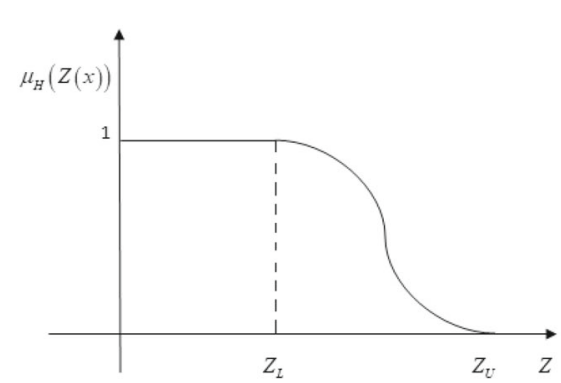

(a) Minimization of objective

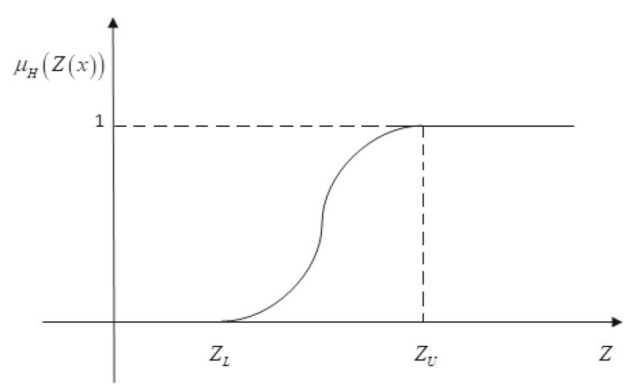

(b) Maximization of objective

$$
\left.+\sum_{j=1}^{k_{2}} w_{j+k_{1}}^{p}\left(\frac{Z_{2 j}-Z_{2 j}^{-}}{Z_{2 j}^{*}-Z_{2 j}^{-}}\right)^{p}\right\}^{1 / p}
$$

where $w_{j}^{\prime} s$ represents the weights and $Z_{i j}^{*}=\max _{(x, y) \in S} Z_{i j}$, $Z_{i j}^{-}=\min _{(x, y) \in S} Z_{i j}$ for $i=1,2 ; j=1,2, \ldots k_{i}$.

To obtain an efficient solution, the problem defined in Eq. (7) is reduced to the following bi-objective optimization problem with conflicting objectives
$d_{p}^{\mathrm{NIS}^{B-}}=\min _{x \in S} d_{p}^{\mathrm{NIS}^{B}}$. Then based on the preference concept, the solution with the shorter distance from PIS and with larger distance from NIS is assigned a larger degree of acceptance. The membership degree of $d_{p}^{\mathrm{PIS}^{B}}$ and $d_{p}^{\mathrm{PIS}^{B}}$ is defined using various linear/non-linear membership functions as defined in Eqs. (14)-(19). To generate a satisfactory solution of multiobjective bi-level optimization problem defined in Eq. (7), a crisp model is to be solved which minimizes the distance from positive ideal solution and maximizes the distance from negative ideal solution while giving some relaxation in the

$\begin{array}{ll}\text { Minimize } & d_{p}^{\mathrm{PIS}^{B}}(x, y) \\ \text { Maximize } & d_{p}^{\mathrm{NIS}^{B}}(x, y)\end{array}$

subject to

$$
\begin{aligned}
& a_{i 1_{k}} x_{1}+a_{i 2_{k}} x_{2}+\ldots+a_{i n_{k}} x_{n_{1}}+ \\
& b_{i 1_{k}} y_{1}+b_{i 2_{k}} y_{2}+\ldots+b_{i n_{k}} y_{n_{2}} ; k=1,2, \ldots, 5 ; i=1,2, \ldots, m \\
& x_{1}, x_{2}, \ldots, x_{n_{1}}, y_{1}, y_{2}, \ldots y_{n_{2}} \geq 0
\end{aligned}
$$

Since both the objectives are usually conflicting to each other, so we solve them separately and let $d_{p}^{\mathrm{PIS}^{B^{*}}}=$ $\min _{x \in S} d_{p}^{\mathrm{PIS}^{B}}, d_{p}^{\mathrm{NIS}^{B^{*}}}=\max _{x \in S} d_{p}^{\mathrm{NIS}^{B}}$ and $d_{p}^{\mathrm{PIS}^{B^{-}}}=\max _{x \in S} d_{p}^{\mathrm{PIS}^{B}}$, decision variables controlled by the leader. A single objective optimization model corresponding to this situation is given by Eq. (24). 
Maximize

subject to

$$
\begin{aligned}
& \mu\left(d_{p}^{\mathrm{PIS}}{ }^{B}\right) \geq \delta \\
& \mu\left(d_{p}^{\mathrm{NIS}^{B}}\right) \geq \delta \\
& \frac{x_{k}-\left(x_{k}^{*}-t_{k}^{L}\right)}{t_{k_{R}}^{L}} \geq \delta ; k=1,2, \ldots, n_{1} \\
& \frac{\left(x_{k}^{*}+t_{k}^{R}\right)-x_{k}}{t_{k}^{R}} \geq \delta ; k=1,2, \ldots, n_{1} \\
& \begin{array}{l}
a_{i 1_{k}} x_{1}+a_{i 2_{k}} x_{2}+\ldots+a_{i n_{k}} x_{n_{1}}+ \\
b_{i 1_{k}} y_{1}+b_{i 2_{k}} y_{2}+\ldots+b_{i n_{k}} y_{n_{2}}
\end{array} \quad \leq r_{i k} ; k=1,2, \ldots, 5 ; i=1,2, \ldots, m \\
& x_{1}, x_{2}, \ldots, x_{n_{1}}, y_{1}, y_{2}, \ldots y_{n_{2}} \geq 0 \\
& \delta \in[0,1]
\end{aligned}
$$

A single objective optimization problem is then modelled using various membership functions explained in Eqs. (14)(19) and an optimal solution to the problem is obtained with the help of various software packages. An optimal solution of Eq. (24) of the form $\left(\delta, x_{1}^{*}, x_{2}^{*}, \ldots, x_{n_{1}}^{*}, y_{1}^{*}, y_{2}^{*}, \ldots, y_{n_{2}}^{*}\right)$ implies that an efficient solution of Eq. (7) is given by $\left(x_{1}^{*}, x_{2}^{*}, \ldots, x_{n_{1}}^{*}, y_{1}^{*}, y_{2}^{*}, \ldots, y_{n_{2}}^{*}\right)$.

\section{Proposed TOPSIS algorithm}

In this section, the modified TOPSIS algorithm proposed is presented to solve the multi-objective bi-level optimization problem under intuitionistic fuzzy environment.

Step 1: Use accuracy function as defined in Eq. (4) and reduce every intuitionistic fuzzy coefficient of objective functions to a crisp coefficient and every intuitionistic fuzzy constraint is reduced to five crisp constraints.

Step 2: Find the maximum and minimum values of all the objective functions at both leader and follower level under the given constraints.

Step 3: Construct a pay off table of positive ideal solution (PIS) of leader and obtain $Z_{1 i}^{*}=\left(Z_{11}^{*}, Z_{12}^{*}, \ldots, Z_{1 k_{1}}^{*}\right)$, the individual optimal solutions.

Step 4: Construct a pay off table of negative ideal solution (NIS) of leader and obtain $Z_{1 i}^{-}=\left(Z_{11}^{-}, Z_{12}^{-}, \ldots, Z_{1 k_{1}}^{-}\right)$, the individual negative ideal solutions.

Step 5: Construct equations for $d_{p}^{\mathrm{PIS}^{u}}$ and $d_{p}^{\mathrm{NIS}}{ }^{u}$ as defined in Eqs. (11) and (12), respectively.

Step 6: Ask the decision maker to select $p$ and $w_{i}, i=$ $1,2, \ldots k_{1}$.

Step 7: Reduce the leader problem to a bi-objective optimization problem as defined in Eq. (10).

Step 8: Optimize both the objectives of model (10) separately and denote them by $\left(d_{p}^{\mathrm{PI} S^{u}}\right)^{*}$ and $\left(d_{p}^{\mathrm{NIS}}{ }^{u}\right)^{*}$.
Step 9: Convert the bi-objective optimization model into a fuzzy goal programming model, where the goal is to find the value of decision variables such that $\left(d_{p}^{\mathrm{PIS}}{ }^{u}\right)$ is approximately equal to $\left(d_{p}^{\mathrm{PIS}^{u}}\right)^{*}$ and $\left(d_{p}^{\mathrm{NIS}}{ }^{u}\right)$ is approximately equal to $\left(d_{p}^{\mathrm{NIS}}\right)^{u}$.

Step 10: Use various linear/non-linear membership function to convert the fuzzy goal programming model into a crisp LPP as defined in Eq. (20).

Step 11: The optimal solution of Eq. (20); $\left(\lambda, x_{1}^{u *}, x_{2}^{u *}, \ldots\right.$, $\left.x_{n_{1}}^{u *}, y_{1}^{u *}, y_{2}^{u *}, \ldots, y_{n_{2}}^{u *}\right)$ implies that the efficient solution of the upper level optimization problem is given by $\left(x_{1}^{u *}, x_{2}^{u *}, \ldots, x_{n_{1}}^{u *}, y_{1}^{u *}, y_{2}^{u *}, \ldots, y_{n_{2}}^{u *}\right)$ based on which the maximum left and right tolerance values; $t_{k}^{L}$ and $t_{k}^{R}$ on the decision variables controlled by the leader are to be defined.

Step 12: Construct a pay off table of positive ideal solution (PIS) of multi-objective bi-level linear programming problem and obtain $Z_{i j}^{*}, i=1,2 ; j=1,2, \ldots n_{i}$, the individual optimal solutions.

Step 13: Construct a pay off table of negative ideal solution (NIS) of multi-objective bi-level optimization problem and obtain $Z_{i j}^{-} ; i=1,2 ; j=1,2, \ldots, n_{i}$, the individual negative ideal solutions.

Step 14: Construct equations for $d_{p}^{\mathrm{PIS} S^{B}}$ and $d_{p}^{\mathrm{NIS}^{B}}$ as defined in Eqs. (21) and (22), respectively.

Step 15: Reduce the multi-objective bi-level optimization problem to a bi-objective optimization problem, as defined in Eq. (23).

Step 16: Optimize both the objectives of Eq. (23) separately and denote them by $d_{p}^{\mathrm{PIS}^{B^{*}}}$ and $d_{p}^{\mathrm{NIS}^{B *}}$, respectively.

Step 17: Formulate the model as given in Eq. (24) for multi-objective bi-level optimization problem using various membership functions.

Step 18: Solve model given by Eq. (24) to get $\left(x^{*}, y^{*}\right)=$ $\left(x_{1}^{*}, x_{2}^{*}, \ldots, x_{n_{1}}^{*}, y_{1}^{*}, y_{2}^{*}, \ldots, y_{n_{2}}^{*}\right)$. 
Step 19: If leader and follower are satisfied with solution in Step 19, go to Step 20, else go to Step 21.

Step 20: Stop with the satisfactory solution, $\left(x^{*}, y^{*}\right)=$ $\left(x_{1}^{*}, x_{2}^{*}, \ldots, x_{n_{1}}^{*}, y_{1}^{*}, y_{2}^{*}, \ldots, y_{n_{2}}^{*}\right)$.

Step 21: Modify the maximum negative and positive tolerance values on the decision variables $\left(x_{1}^{u *}, x_{2}^{u *}, \ldots, x_{n_{1}}^{u *}\right)$, $t_{k}^{L}$ and $t_{k}^{R}, k=1,2, \ldots n_{1}$ and go to Step 17.

\section{Production planning problem}

The production planning problem of manufacturing firms are considered. The model for the problems are constructed and then are solved with the help of methodology proposed in this work.

\section{Problem 1}

A manufacturing firm produces three commodities, say A, $\mathrm{B}$ and $\mathrm{C}$. The objective is to find the number of units of each commodity that should be produced so that the decision makers at both the levels are satisfied with the production. The decision maker at the upper level comprises of central governmental authorities which controls the production of commodity A and aims at minimizing the waste product generation and power consumption. The decision maker at the be produced without power. Each commodity requires some manufacturing time, packaging time and some initial capital investment. The figures for manufacturing time of commodity $\mathrm{A}, \mathrm{B}$ and $\mathrm{C}$ are $\tilde{2^{I}}, \tilde{4^{I}}$ and $\tilde{3^{I}}$ and the corresponding figures for packaging time are $\tilde{3^{I}}, \tilde{2^{I}}$ and $\tilde{2^{I}}$ hours. The initial capital investment required per unit of $\mathrm{A}, \mathrm{B}$ and $\mathrm{C}$ are $\tilde{0}^{I}, 1 \tilde{5}^{I}$ and $\tilde{5^{I}}$. The production of $\mathrm{A}$ is controlled by the government and at least $\tilde{5}^{I}$ units of $\mathrm{A}$ are to be produced. The number of units of $\mathrm{B}$ commodity produced should be at least twice the number of units of $\mathrm{C}$ for the better position in the market. The total production of the company should be greater than $\tilde{40}^{I}$. The number of units of each commodity in a week is to be calculated when $1 \tilde{80}^{I}$ hours of manufacturing time, $1 \tilde{00}^{I}$ hours of packaging time and an initial capital investment of $500^{I}$ is made available.

A model for the explained production planning problem in an intuitionistic fuzzy environment is given by Eq. (25) which is then solved using Proposed TOPSIS algorithm. Let $x_{1}, x_{2}$ and $x_{3}$ represent the units of commodity $\mathrm{A}, \mathrm{B}$ and $\mathrm{C}$ that should be produced. Here $\tilde{Z_{11}^{I}}\left(x_{1}, x_{2}, x_{3}\right), \tilde{Z_{12}^{I}}\left(x_{1}, x_{2}, x_{3}\right)$ be the objectives of the upper level DM which represents the waste product generation and power consumption, respectively, and $\tilde{Z}_{21}^{I}\left(x_{1}, x_{2}, x_{3}\right), \tilde{Z_{22}^{I}}\left(x_{1}, x_{2}, x_{3}\right)$ be the objectives of the lower level DM which represents the total profit earned and revenues given to the government.

$$
\begin{aligned}
& \text { Minimize, Minimize } \quad \tilde{Z}_{1}^{I}\left(x_{1}, x_{2}, x_{3}\right)=\left[\tilde{Z_{11}^{I}}\left(x_{1}, x_{2}, x_{3}\right), \tilde{Z_{12}^{I}}\left(x_{1}, x_{2}, x_{3}\right)\right] \\
& \text { where } x_{2}, x_{3} \text { solves } \\
& \text { Maximize, Minimize } \\
& \text { subject to } \\
& \tilde{Z_{2}^{I}}\left(x_{1}, x_{2}, x_{3}\right)=\left[\tilde{Z_{21}^{I}}\left(x_{1}, x_{2}, x_{3}\right), \tilde{Z_{22}^{I}}\left(x_{1}, x_{2}, x_{3}\right)\right] \\
& \tilde{2}^{I} x_{1}+\tilde{4}^{I} x_{2}+\tilde{3}^{I} x_{3} \leq 1 \tilde{8} 0^{I} \text { (manufacturing time) } \\
& \tilde{3}^{I} x_{1}+\tilde{2}^{I} x_{2}+\tilde{2}^{I} x_{3} \leq 1 \tilde{0} 0^{I} \text { (packaging time) } \\
& \tilde{10}^{I} x_{1}+1 \tilde{5}^{I} x_{2}+\tilde{5}_{a}^{I} x_{3} \leq 5 \tilde{0} 0^{I} \text { (initial capital) } \\
& \tilde{1}^{I} x_{1} \geq{\tilde{5_{b}}}^{I} \text { (Decision controlled by leader) } \\
& \tilde{1}^{I} x_{2} \geq \tilde{2}^{I} x_{3} \text { (better position in market) } \\
& \tilde{1}^{I} x_{1}+\tilde{1}^{I} x_{2}+\tilde{1}^{I} x_{3} \geq \tilde{40}^{I} \text { (market demand) } \\
& x_{1}, x_{2}, x_{3} \geq 0
\end{aligned}
$$

lower level comprises of the organization running the manufacturing company and it aims at maximizing the total profit earned and minimize the revenue to be given to the government. The profit contribution of commodities A, B and C per unit are $\tilde{5^{I}}, \tilde{4^{I}}$ and $\tilde{3^{I}}$, respectively, and the revenue given to the government in the same order per unit of commodities are $\tilde{2^{I}}, \tilde{3^{I}}$ and $\tilde{0^{I}}$. The waste generated per unit of commodity $\mathrm{A}, \mathrm{B}$ and $\mathrm{C}$ is $\tilde{2^{I}}, \tilde{1^{I}}$ and $\tilde{2^{I}}$ whereas the power needed to produce one unit of $\mathrm{B}$ and $\mathrm{C}$ is $\tilde{4}^{I}$ and $\tilde{5^{I}}$, respectively. A can where

$$
\begin{aligned}
\tilde{Z_{11}^{I}}\left(x_{1}, x_{2}, x_{3}\right)= & (1,2,3 ; 0,2,4) x_{1}+(0.5,1,1.5 ; 0,1,2) x_{2} \\
& +(1,2,3 ; 0,2,4) x_{3} \\
\tilde{Z_{12}^{I}}\left(x_{1}, x_{2}, x_{3}\right)= & (2,4,6 ; 0,4,8) x_{2}+(4,5,6 ; 3,5,7) x_{3} \\
\tilde{Z_{21}^{I}}\left(x_{1}, x_{2}, x_{3}\right)= & (4,5,6 ; 3,5,7) x_{1}+(2,4,6 ; 0,4,8) x_{2} \\
& +(2,3,4 ; 1,3,5) x_{3} \\
\tilde{Z_{22}^{I}}\left(x_{1}, x_{2}, x_{3}\right)= & (1,2,3 ; 0,2,4) x_{1}+(2,3,4 ; 1,3,5) x_{2}
\end{aligned}
$$


and
Converting the bi objective optimization problem to a goal programming model gives:

$$
\begin{array}{lll}
\tilde{2}^{I}=(1,2,3 ; 0,2,4) & \tilde{4}^{I}=(3,4,5 ; 2,4,6) & 1 \tilde{8} 0^{I}=(100,180,260 ; 60,180,300) \\
\tilde{3}^{I}=(2,3,4 ; 1,3,5) & \tilde{10}^{I}=(8,10,12 ; 5,10,15) & 100^{I}=(50,100,150 ; 20,100,180) \\
\tilde{\tilde{a}_{a}^{I}}=(3,5,7 ; 0,5,10) & \tilde{15}^{I}=(13,15,17 ; 10,15,20) & 5 \tilde{50} 0^{I}=(400,500,600 ; 300,500,700) \\
{\tilde{5_{b}}}^{I}=(2.5,5,7.5 ; 0,5,10) & \tilde{1}^{I}=(0.5,1,1.5 ; 0,1,2) & \tilde{40}^{I}=(20,40,60 ; 0,40,80)
\end{array}
$$

Using the accuracy function, every intuitionistic fuzzy coefficient of objective function can be reduced to a crisp coefficient and each intuitionistic fuzzy constraint can be reduced to five crisp constraints. Let $S$ denotes the set of crisp constraints corresponding to intuitionistic fuzzy constraints. The individual maximum and minimum value of all the objectives in two levels are given in Table 2 .

The positive ideal solution pay off table for the leader is shown by Table 3 and thus $\left(Z_{11}^{*}, Z_{12}^{*}\right)=(54.6667,127)$.

The negative ideal solution pay off table for the leader is shown by Table 4 and thus $\left(Z_{11}^{-}, Z_{12}^{-}\right)=(61.5385,154.375)$.

The equation for $d_{p}^{\mathrm{PIS}^{u}}$ and $d_{p}^{\mathrm{NIS}}{ }^{u}$ can be formulated by taking $w_{1}=w_{2}=\frac{1}{2}$ and $p=2$.

The maximum and minimum values of $d_{p}^{\mathrm{PIS}}{ }^{u}$ are 0.6530497 and 0.1552311 , respectively. The maximum and minimum values of $d_{p}^{\mathrm{NIS}^{u}}$ are 0.513403 and 0.07710929 , respectively. Thus, $\left(d_{p}^{\mathrm{PIS}^{u *}}, d_{p}^{\mathrm{NIS}}{ }^{u *}\right)=(0.1552311,0.513403)$.

Table 2 Maximum and minimum values

\begin{tabular}{lllll}
\hline & $Z_{11}$ & $Z_{12}$ & $Z_{21}$ & $Z_{22}$ \\
\hline Maximum & 61.5385 & 154.375 & 165.625 & 89 \\
Minimum & 54.666 & 127 & 153.33 & 80 \\
\hline
\end{tabular}

Table 3 PIS pay off for leader

\begin{tabular}{lllll}
\hline$Z_{11}$ & $Z_{12}$ & $x_{1}$ & $x_{2}$ & $x_{3}$ \\
\hline $54.6667^{*}$ & 147.997 & 5.333 & 25.333 & 9.333 \\
57 & $127^{*}$ & 10 & 23 & 7 \\
\hline
\end{tabular}

Table 4 NIS pay off for Leader

\begin{tabular}{lllll}
\hline$Z_{11}$ & $Z_{12}$ & $x_{1}$ & $x_{2}$ & $x_{3}$ \\
\hline $61.5385^{-}$ & 149.999 & 7.6923 & 23.07692 & 11.53846 \\
57.5 & $154.375^{-}$ & 5.00 & 23.75 & 11.875 \\
\hline
\end{tabular}

Find $\quad\left(x_{1}, x_{2}, x_{3}\right)$

subject to

$$
\begin{aligned}
& d_{p}^{\mathrm{PIS}^{U}} \approx 0.1552311 \\
& d_{p}^{\mathrm{NIS}^{U}} \approx 0.513403 \\
& \text { and } x \in S
\end{aligned}
$$

Solving the crisp LPP corresponding to (27) using linear membership function, we get $\left(\lambda, x_{1}^{*}, x_{2}^{*}, x_{3}^{*}\right)=$ $(0.6165644,5.849917,24.8850,9.265083)$. Let the upper level decision maker decides $x_{1}=5.849917$ with 2 as positive and negative tolerance limits.

The positive ideal solution pay off table and the negative ideal solution pay off table for the follower is shown by Tables 5 and 6 and thus $\left(Z_{21}^{*}, Z_{22}^{*}\right)=(165.625,80)$ and $\left(Z_{21}^{-}, Z_{22}^{-}\right)=(153.33,89)$.

The equation for $d_{p}^{\mathrm{PIS}^{B}}$ and $d_{p}^{\mathrm{NIS}^{B}}$ is formulated by taking $w_{1}=w_{2}=w_{3}=w_{4}=\frac{1}{4}$ and $p=2$ and then the proposed TOPSIS method is used to find efficient solution. Applying various models from Eq.(14)-(19) and solving by LINGO, the optimal solution to the problem (25) using various membership functions is given by Table 7 . The degree of satisfaction of various objectives using different membership functions is represented by Fig. 5 .

A comparison between the proposed approach and the approach defined in [24] is given in Table 8. The method in [24] does not take into account the hesitation in coefficients of objective functions and intuitionistic fuzzy coefficients are defuzzified in the very first step which results in the loss of

Table 5 PIS pay off for follower

\begin{tabular}{lllll}
\hline$Z_{21}$ & $Z_{22}$ & $x_{1}$ & $x_{2}$ & $x_{3}$ \\
\hline $165.625^{*}$ & 85.9375 & 7.8125 & 23.4375 & 10.9375 \\
160 & $89^{*}$ & 10 & 20 & 10 \\
\hline
\end{tabular}

Table 6 NIS pay off for follower

\begin{tabular}{lllll}
\hline$Z_{21}$ & $Z_{22}$ & $x_{1}$ & $x_{2}$ & $x_{3}$ \\
\hline $153.33^{-}$ & 79.99 & 5 & 23.33 & 11.66 \\
163 & $89^{-}$ & 10 & 23 & 7 \\
\hline
\end{tabular}


Table 7 Solutions for Problem 1

\begin{tabular}{llll}
\hline & Linear function & Parabolic function & Hyperbolic function \\
\hline$\left(x_{1}, x_{2}, x_{3}\right)$ & $(6.7028,23.1137,10.1834)$ & $(6.1449,23.6826,10.1724)$ & $(6.9859,22.093,11.0046)$ \\
$\delta$ & 0.5735036 & 0.1909812 & 0.5002931 \\
$Z_{11}$ & 56.886306 & 56.317388 & 58.0748 \\
$Z_{12}$ & 143.37185 & 145.59288 & 143.3974 \\
$Z_{21}$ & 156.519495 & 155.97244 & 156.31789 \\
$Z_{22}$ & 82.746886 & 83.337668 & 80.25244 \\
\hline
\end{tabular}

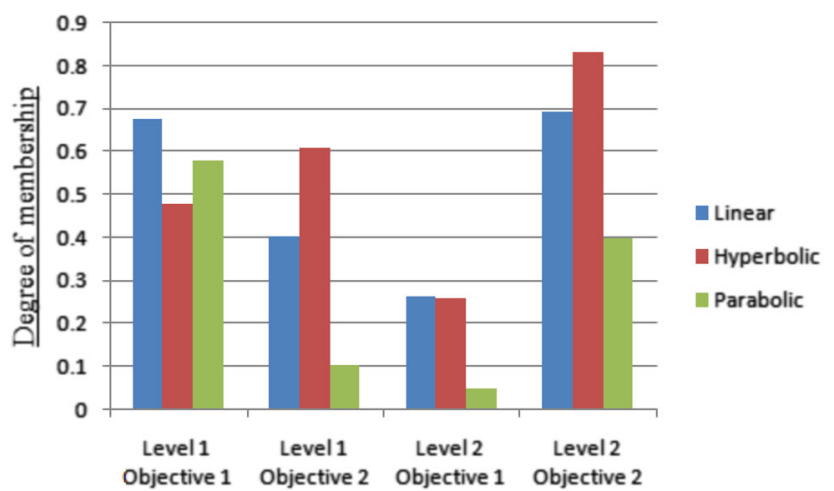

Fig. 5 Comparison of Various membership functions for Problem 1

information and reduction of the problem to a crisp multiobjective bi-level optimization problem.

\section{Problem 2}

Assume that a manufacturing firm produces packets of two commodities, say A and B. Government authorities serves as the leader and controls the production of packets of $\mathrm{A}$ and firm owner serves as the follower. Government authorities wish to maximize their revenue and minimize the carbon emission. Firm owners wish to maximize the production and the profit earned. The profit earned per packet of commodity $\mathrm{A}$ and $\mathrm{B}$ are $\tilde{3}^{I}$ and $\tilde{8}^{I}$, respectively. The revenues given to the government per packet of commodity A and B are $\tilde{5}^{I}$ and $\tilde{2}^{I}$, respectively, and the carbon emission produced per packet of commodity A and B are $\tilde{3}^{I}$ and $\tilde{2}^{I}$, respectively. Both the products can be made with the help of two machines. One packet of commodity A requires $\tilde{2}^{I}$ hours on first machine and $\tilde{4}^{I}$ hours on second machine. One packet of commodity
B requires $\tilde{5}^{I}$ hours on first machine and $\tilde{2}^{I}$ hours on second machine. The objective is to find the number of packets of A and B that should be manufactured with $\tilde{10}^{I}$ hours of first machine time and $\tilde{12}^{I}$ hours of second machine time to meet the market demand of atleast $\tilde{2}^{I}$ packets.

A model for the above stated production planning problem in an intuitionistic fuzzy environment is given by Eq. (28) which is then solved by proposed TOPSIS algorithm. Let $x_{1}$ and $x_{2}$ represent the packets of commodity $\mathrm{A}$ and $\mathrm{B}$ that should be produced. Here, $\tilde{Z}_{11}^{I}\left(x_{1}, x_{2}\right), \tilde{Z_{12}^{I}}\left(x_{1}, x_{2}\right)$ be the objectives of the upper level DM which represents the revenues generates and carbon emissions, respectively, and $\tilde{Z}_{21}^{I}\left(x_{1}, x_{2}\right), \tilde{Z_{22}^{I}}\left(x_{1}, x_{2}\right)$ be the objectives of the lower level DM which represents the packets produced and profit earned, respectively.

$$
\begin{array}{ll}
\begin{array}{l}
\text { Maximize, Minimize } \\
x_{1}
\end{array} & \tilde{Z}_{1}^{I}\left(x_{1}, x_{2}\right)=\left[\tilde{Z_{11}^{I}}\left(x_{1}, x_{2}\right), \tilde{Z_{12}^{I}}\left(x_{1}, x_{2}\right)\right] \\
\text { where } x_{2}, x_{3} \text { solves } & \\
\begin{array}{ll}
\text { Maximize, Maximize } \\
\text { subject to }
\end{array} & \tilde{Z}_{2}^{I}\left(x_{1}, x_{2}\right)=\left[\tilde{Z_{21}^{I}}\left(x_{1}, x_{2}\right), \tilde{Z_{22}^{I}}\left(x_{1}, x_{2}\right)\right] \\
\tilde{2}^{I} x_{1}+\tilde{5}^{I} x_{2} \leq \tilde{10}^{I} \text { (first machine hours) } \\
\tilde{4}^{I} x_{1}+\tilde{2}^{I} x_{2} \leq \tilde{12}^{I} \text { (second machine hours) } \\
\tilde{1}^{I} x_{1}+\tilde{1}^{I} x_{2} \geq \tilde{2}^{I} \text { (market demand) } \\
x_{1}, x_{2} \geq 0
\end{array}
$$

where

$$
\begin{aligned}
\tilde{Z_{11}^{I}}\left(x_{1}, x_{2}\right) & =(3,5,7 ; 1,5,9) x_{1}+(1,2,3 ; 0,2,4) x_{2} \\
\tilde{Z_{12}^{I}}\left(x_{1}, x_{2}\right) & =(2,3,4 ; 1,3,5) x_{2}+(1,2,3 ; 0,2,4) x_{3} \\
\widetilde{Z_{21}^{I}}\left(x_{1}, x_{2}\right) & =(0.5,1,1.5 ; 0,1,2) x_{1}+(0.5,1,1.5 ; 0,1,2) x_{2} \\
Z_{22}^{I}\left(x_{1}, x_{2}\right) & =(2,3,4 ; 1,3,5) x_{1}+(6,8,10 ; 4,8,12) x_{2}
\end{aligned}
$$

Table 8 Comparison of various solutions of Problem 1

\begin{tabular}{lll}
\hline & Final solution & Satisfactory degree \\
\hline Linear membership function & $(6.702893,23.11370,10.18341)$ & 0.5735036 \\
Parabolic membership function & $(6.144904,23.68262,10.17248)$ & 0.1909812 \\
Hyperbolic membership function & $(6.985970,22.0935,11.00468)$ & 0.5002930 \\
IFO technique as in [24] & $(1.2234568,8.732510,4.199588)$ & 0.01791839
\end{tabular}


Table 9 Solutions for Problem 2

\begin{tabular}{llll}
\hline & Linear function & Parabolic function & Hyperbolic function \\
\hline$\left(x_{1}, x_{2}\right)$ & $(1.561102,0.87796)$ & $(1.670181,0.6596385)$ & $(1.732006,0.5359882)$ \\
$\delta$ & 0.5422036 & 0.138518 & 0.2571697 \\
$Z_{11}$ & 9.56143 & 9.670182 & 9.7320064 \\
$Z_{12}$ & 6.439226 & 6.32982 & 6.2679944 \\
$Z_{21}$ & 2.439062 & 2.3298195 & 2.2679942 \\
$Z_{22}$ & 11.706986 & 10.287651 & 9.4839236 \\
\hline
\end{tabular}

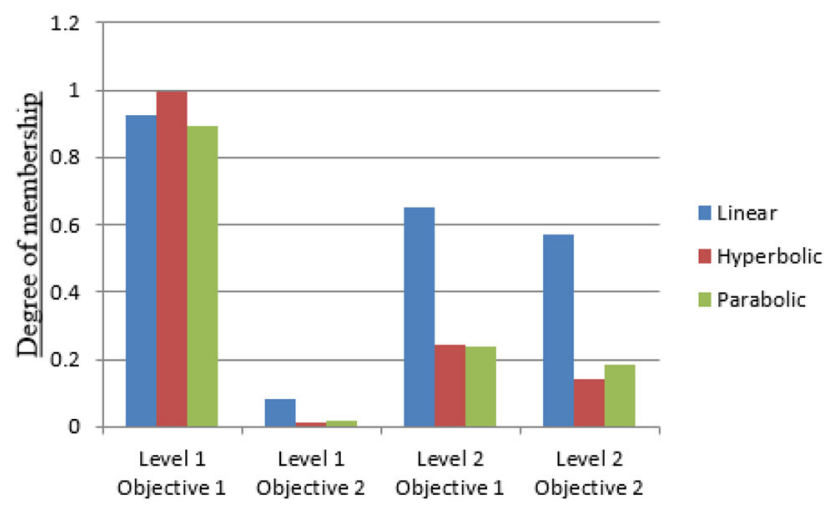

Fig. 6 Comparison of Various membership functions for problem 2
After obtaining a satisfactory solution for the leader level optimization problem, the decision variables controlled by leader are relaxed with the help of several linear and nonlinear membership functions so as to extend the feasible region for the follower. The left and right satisfactory levels of decision variable controlled by the leader should be done while keeping in mind the non-negativity constraints. It is discovered that the satisfaction of the decision maker follows the order, Linear $>$ Hyperbolic $>$ Parabolic, in the case of given numerical examples.

Addition of a constraint may lead to the rank reversal of the alternatives and this comes up as a major limitation of the proposed model. In the proposed approach, the choice

and

$$
\begin{array}{lll}
\tilde{2}^{I}=(1,2,3 ; 0,2,4) & \tilde{4}^{I}=(2,4,6 ; 0,4,8) & \tilde{10}^{I}=(6,10,14 ; 4,10,16) \\
\tilde{5}^{I}=(3,5,7 ; 2,5,8) & \tilde{1}^{I}=(0.5,1,1.5 ; 0,1,2) & \tilde{12}^{I}=(10,12,14 ; 8,12,16)
\end{array}
$$

The solution of the problem given by Eq. (28) by using various membership functions is given by Table 9 .

The degree of satisfaction of various objectives using different membership functions is represented by Fig. 6 .

The comparison of the proposed method with the method presented in [24] for Problem 2 is given in the Table 10.

\section{Conclusion}

In this paper, a concept for solving multi-objective bi-level linear optimization problem in intuitionistic fuzzy environment is introduced. The concept of intuitionistic fuzzy environment not only allows one to define a degree of membership but also a degree of non-membership; which is not simply the complement of membership degree. The problem is reduced to a conventional multi-objective bi-level optimization problem using accuracy function and comparison of two IFNs. A satisfactory solution for the multi-objective problems at both the levels is acquired using TOPSIS method. of weights to upper level decision makers' problem (when both the levels have different number of objectives) may land us in a position when upper level objectives are not taken proper care of. However, this problem can be solved by manually updating the weights of all the objectives. In this work, a real world application of the proposed problem has been explained in the production planning process of a manufacturing company. The proposed model can be extended for solving Multi-level multi-objective optimization problems, which can be applied in hierarchical decision making process. The model can also be used for solving bi-level multi-objective fractional programming problems. The study of fractional objectives is necessary because they prove to be a better tool to measure the efficiency of the system. The approach presented in this work can be implemented on a complete real life problem from an industry such as manufacturing, scheduling, transportation, communication networks and many more which involves multi-objective hierarchical decision making in an uncertain environment. 
Table 10 Comparison of various solutions of Problem 2

\begin{tabular}{lll}
\hline & Final solution & Satisfactory degree \\
\hline Linear membership function & $(1.561102,0.87796)$ & 0.5422036 \\
Parabolic membership function & $(1.670181,0.6596285)$ & 0.138518 \\
Hyperbolic membership function & $(1.732006,0.5359882)$ & 0.2571697 \\
IFO technique as in [24] & $(0.8899,0.5119668)$ & 0.056 \\
\hline
\end{tabular}

\section{Declarations}

Conflict of interest On behalf of all authors, the corresponding author states that there is no conflict of interest.

Open Access This article is licensed under a Creative Commons Attribution 4.0 International License, which permits use, sharing, adaptation, distribution and reproduction in any medium or format, as long as you give appropriate credit to the original author(s) and the source, provide a link to the Creative Commons licence, and indicate if changes were made. The images or other third party material in this article are included in the article's Creative Commons licence, unless indicated otherwise in a credit line to the material. If material is not included in the article's Creative Commons licence and your intended use is not permitted by statutory regulation or exceeds the permitted use, you will need to obtain permission directly from the copyright holder. To view a copy of this licence, visit http://creativecomm ons.org/licenses/by/4.0/.

\section{References}

1. Candler W, Townsley R (1982) A linear two-level programming problem. Comp Oper Res 9(1):59-76

2. Wen UP, Hsu ST (1991) Linear bi-level programming problems' a review. J Oper Res Soc 42(2):125-133

3. Singh VP, Chakraborty D (2017) Solving bi-level programming problem with fuzzy random variable coefficients. J Intell Fuzzy Syst 32(1):521-528

4. Dempe S (2003) Annotated bibliography on bilevel programming and mathematical programs with equilibrium constraints. J Math Program Oper Res 52(3):333-359

5. Singh VP, Chakraborty D (2019) Bi-level optimization based on fuzzy if-then rule. Croat Oper Res Rev 10:315-328

6. Moitra BN, Pal BB (2002) A fuzzy goal programming approach for solving bilevel programming problems. In: AFSS International Conference on Fuzzy Systems, pp 91-98. Springer

7. Arora SR, Gupta R (2009) Interactive fuzzy goal programming approach for bilevel programming problem. Eur J Oper Res 194(2):368-376

8. Wan Z, Wang G, Hou K (2008) An interactive fuzzy decision making method for a class of bilevel programming. In: 2008 Fifth International Conference on Fuzzy Systems and Knowledge Discovery, volume 1, pp 559-564. IEEE

9. Zheng Y, Liu J, Wan Z (2014) Interactive fuzzy decision making method for solving bilevel programming problem. Appl Math Model 38(13):3136-3141

10. Pramanik S, Roy TK (2007) Fuzzy goal programming approach to multilevel programming problems. Eur J Oper Res 176(2):11511166

11. Sinha S (2003) Fuzzy programming approach to multi-level programming problems. Fuzzy Sets Syst 136(2):189-202
12. Maiti SK, Roy SK (2019) Bi-level programming for stackelberg game with intuitionistic fuzzy number: a ranking approach. J Oper Res Soc China 9(1):1-19

13. Said R, Bechikh S, Louati A, Aldaej A, Said LB (2020) Solving combinatorial multi-objective bi-level optimization problems using multiple populations and migration schemes. IEEE Access 8(1):141674-141695

14. Vidhya R, Irene Hepzibah R (2017) A comparative study on interval arithmetic operations with intuitionistic fuzzy numbers for solving an intuitionistic fuzzy multi-objective linear programming problem. Int J Appl Math 27(3):563-573

15. Biswas A, De AK (2016) An efficient ranking technique for intuitionistic fuzzy numbers with its application in chance constrained bilevel programming. Adv Fuzzy Syst 2016(1):1-12

16. Nasseri SH, Goli M, Bavandi S (2018) An approach for solving linear programming problem with intuitionistic fuzzy objective coefficient. In: 2018 6th Iranian Joint Congress on Fuzzy and Intelligent Systems (CFIS), pp 105-107. IEEE

17. Ahmad F (2021) Robust neutrosophic programming approach for solving intuitionistic fuzzy multiobjective optimization problems. Complex Intell Syst 7(4):1-20

18. Ghosh S, Roy SK, Ebrahimnejad A, Verdegay JL (2021) Multiobjective fully intuitionistic fuzzy fixed-charge solid transportation problem. Complex Intell Syst 7(2):1009-1023

19. Ebrahimnejad A, Verdegay JL (2018) A new approach for solving fully intuitionistic fuzzy transportation problems. Fuzzy Optim Decis Mak 17(4):447-474

20. Gupta S, Haq A, Ali I, Sarkar B (2021) Significance of multiobjective optimization in logistics problem for multi-product supply chain network under the intuitionistic fuzzy environment. Complex Intell Syst 7(4):2119-2139

21. Alessa NA (2021) Bi-level linear programming of intuitionistic fuzzy. Soft Comput 25(13):8635-8641

22. Zhao X, Zheng Y, Wan Z (2017) Interactive intuitionistic fuzzy methods for multilevel programming problems. Expert Syst Appl 72(1):258-268

23. Lv Y, Wang S, Gao Z, Cheng G, Huang G, He Z (2020) A sustainable road pricing oriented bilevel optimization approach under multiple environmental uncertainties. Int J Sustain Transp 1:1-28

24. Aggarwal S, Gupta C (2013) Bi-level multi-objective linear programming under intuitionistic fuzzy environment. Int J Pure Appl Sci Technol 17(2):45-61

25. Malik M, Gupta S.K, Ahmad I (2021) A new approach to solve fully intuitionistic fuzzy linear programming problem with unrestricted decision variables. J Intell Fuzzy Syst 1(Preprint):1-14

26. Abbassi M, Chaabani A, Said LB (2021) An efficient chemical reaction algorithm for multi-objective combinatorial bi-level optimization. Eng Optim 1(1):1-22

27. Del Valle A, Wogrin S, Reneses J (2020) Multi-objective bilevel optimization model for the investment in gas infrastructures. Energy Strategy Rev 30(1):100492

28. Cao C, Liu Y, Tang O, Gao X (2021) A fuzzy bi-level optimization model for multi-period post-disaster relief distribution in sustainable humanitarian supply chains. Int J Prod Econ 235(1):1-14 
29. Deb K, Sinha A, Malo P, Lu Z (2020) Approximate bilevel optimization with population-based evolutionary algorithms. In: Bilevel Optimization, pp 361-402. Springer

30. Zimmermann HJ (1978) Fuzzy programming and linear programming with several objective functions. Fuzzy Sets Syst 1(1):45-55

31. Chuong TD (2020) Optimality conditions for nonsmooth multiobjective bilevel optimization problems. Ann Oper Res 287(2):617642

32. Gadhi N, Hamdaoui K, El Idrissi M (2020) Optimality conditions for a multiobjective bilevel optimization problem involving set valued constraints. Optimization 70(9):2013-2029

33. Tzeng GH, Huang JJ (2011) Multiple attribute decision making: methods and applications. CRC press, Boca Raton

34. Abo-Sinna MA, Amer AH (2005) Extensions of topsis for multiobjective large-scale nonlinear programming problems. Appl Math Comput 162(1):243-256

35. Abo-Sinna MA (2000) Extensions of the topsis for multi-objective dynamic programming problems under fuzziness. Adv Model Anal 43(4): $1-24$

36. Chen CT (2000) Extensions of the topsis for group decision-making under fuzzy environment. Fuzzy Sets Syst 114(1):1-9

37. Baky IA, Abo-Sinna MA (2013) Topsis for bi-level modm problems. Appl Math Model 37(3):1004-1015

38. Atanassov K (2016) Intuitionistic fuzzy sets. Int J Bioautom 20:1

39. Bellman RE, Zadeh la (1970) Decision-making in a fuzzy environment. Manag Sci 17(4):B-141

40. Parvathi R, Malathi C (2012) Intuitionistic fuzzy linear programming problems. World Appl Sci J 17(12):1802-1807

41. Jana B, Roy TK (2007) Multi-objective intuitionistic fuzzy linear programming and its application in transportation model. Not Intuit Fuzzy Sets 13(1):34-51
42. Atan Ö, Kutlu F, Castillo O (2020) Intuitionistic fuzzy sliding controller for uncertain hyperchaotic synchronization. Int J Fuzzy Syst 22(5):1430-1443

43. Castillo O, Kutlu F, Atan Ö (2020) Intuitionistic fuzzy control of twin rotor multiple input multiple output systems. J Intell Fuzzy Syst 38(1):821-833

44. Kutlu F, Atan Ö, Silahtar O (2020) Intuitionistic fuzzy adaptive sliding mode control of nonlinear systems. Soft Comput 24(1):5364

45. Sotirov S, Sotirova E, Atanassova V, Atanassov K, Castillo O, Melin P, Petkov T, Surchev S (2018) A hybrid approach for modular neural network design using intercriteria analysis and intuitionistic fuzzy logic. Complexity 1:2018

46. Singh SK, Yadav SP (2018) Intuitionistic fuzzy multi-objective linear programming problem with various membership functions. Ann. Oper. Res. 269(1):693-707

Publisher's Note Springer Nature remains neutral with regard to jurisdictional claims in published maps and institutional affiliations. 